\title{
Correlation between DEC1/DEC2 and epithelial-mesenchymal transition in human prostate cancer PC-3 cells
}

\author{
QIANG LIU ${ }^{1,2}$, YUNYAN WU ${ }^{1}$, HIROKO SEINO ${ }^{1}$, TOSHIHIRO HAGA ${ }^{1}$, \\ TADASHI YOSHIZAWA $^{1}$, SATOKO MOROHASHI ${ }^{1}$ and HIROSHI KIJIMA ${ }^{1}$ \\ ${ }^{1}$ Department of Pathology and Bioscience, Hirosaki University Graduate School of Medicine, Hirosaki, \\ Aomori 036-8562, Japan; ${ }^{2}$ Department of Nephrology, The First Hospital of China Medical University, \\ Shenyang, Liaoning 110001, P.R. China
}

Received December 26, 2017; Accepted July 4, 2018

DOI: $10.3892 / \mathrm{mmr} .2018 .9367$

\begin{abstract}
Differentiated embryonic chondrocyte (DEC) genes have been reported to be involved in the regulation of mammalian circadian rhythms, differentiation, apoptosis, the response to hypoxia and epithelial-mesenchymal transition (EMT). Activation of transforming growth factor (TGF) $\beta$ signaling is known to promote EMT for the development of metastatic castration-resistant prostate cancer (PCa). However, the role of DEC genes in the TGF- $\beta$-induced EMT of PCa remains unclear. In the present study it was demonstrated that TGF- $\beta$ increased the transcriptional/translational levels of DEC1 but decreased those of DEC2 in PC-3 cells. Moreover, TGF- $\beta$ evoked the phosphorylation of Smad2, followed by the activation of mesenchymal markers, such as $\mathrm{N}$-cadherin and vimentin, in addition to the suppression of epithelial markers, such as E-cadherin. The knockdown of DEC1 restrained TGF- $\beta$-induced cell morphology changes as well as cell motility, which was compatible with the upregulation of E-cadherin and downregulation of pSmad2, N-cadherin, and vimentin. However, DEC2 knockdown endorsed PC-3 cells with a more metastatic phenotype. EMT-related markers in DEC2 siRNA-transfected cells exhibited a reverse expression pattern when compared with that in DEC1 siRNA-transfected cells. Taken together, these results provide evidence that DEC1 and DEC2 have opposite effects on TGF- $\beta$-induced EMT in human prostate cancer PC-3 cells.
\end{abstract}

Correspondence to: Dr Yunyan Wu, Department of Pathology and Bioscience, Hirosaki University Graduate School of Medicine, 5 Zaifu-cho, Hirosaki, Aomori 036-8562, Japan

E-mail: yunyanwu@hirosaki-u.ac.jp

Abbreviations: DEC1, differentiated embryonic chondrocyte gene 1; DEC2, differentiated embryonic chondrocyte gene 2; EMT, epithelial-mesenchymal transition; ADT, androgen deprivation therapy; TGF- $\beta$, transforming growth factor-beta; DAPI, 4', 6-diamidino-2-phenylindole

Key words: differentiated embryonic chondrocyte gene 1, differentiated embryonic chondrocyte gene 2, EMT, TGF- $\beta$, PC-3 cells

\section{Introduction}

Prostate cancer (PCa) is the third most common cause of cancer-related deaths among men in the United States, accounting for an estimated 26,730 deaths in 2016 (1). Recently, the incidence of PCa in Asian countries has also markedly increased. The majority of PCa patients who respond well to androgen deprivation therapy (ADT) will eventually progress to castration-resistant prostate cancer (CRPC) within 1-3 years, at which point the median survival rate is reduced to only 12-15 months (2). Bone metastasis occurs in approximately $90 \%$ of patients with advanced $\mathrm{PCa}(3)$, and this severely affects the life quality of PCa patients (4). Therefore, it is necessary to identify novel targets for therapeutic intervention in PCa.

The epithelial-mesenchymal transition (EMT) is recognized as an important process during several phases of embryonic development. It is often marked by a loss of expression of E-cadherin and a gain expression of $\mathrm{N}$-cadherin and vimentin. Accumulated evidence has indicated that the EMT is a critical process to facilitate metastasis in various types of cancer including CRPC $(5,6)$. The EMT can be induced by a variety of stimuli including growth factors, cytokines, and hypoxia (7). Transforming growth factor (TGF) $-\beta$ is one of the most prominent extracellular inducers of the EMT. Although studies have demonstrated that TGF- $\beta$ can inhibit the proliferation of tumor cells during the early stages of tumor development, it can locally result in greater tumor invasiveness through the induction of the EMT during the advanced stages of cancer (8-10). At present, it is known that TGF- $\beta$ participates in the EMT through the canonical and non-canonical TGF- $\beta$ signaling pathways. For the canonical TGF- $\beta /$ Smad signaling pathway, the direct binding of TGF- $\beta$ to its receptors leads to the phosphorylation of the Smad proteins, which form transcription factor complexes that regulate the expression of TGF- $\beta$-responsive genes $(11,12)$. TGF- $\beta$ also activates a variety of non-canonical pathways, including the MAPK, Rho-like GTPase, and PI3K-AKT-mTOR pathways (13). Elevated TGF- $\beta$ expression was observed in advanced PCa with higher Gleason scores, where it showed a negative correlation with clinical outcome $(14,15)$. 
Differentiated embryonic chondrocyte gene (DEC) 1 and DEC2 are members of the basic helix-loop-helix (bHLH) transcription factor family and have been implicated as signaling mediators of diverse biological events including cell proliferation, circadian rhythms, apoptosis, tumorigenesis, and the response to hypoxia (16-19). In our preliminary study, we showed that DEC1 promoted TGF- $\beta$-induced EMT in human pancreatic cancer PANC-1 cells (20). However, the roles of DEC1 and DEC2 in the EMT progress as well as their relations with TGF- $\beta$ in PCa cells remain undetermined.

The aim of the present study was to elucidate the effects of DEC on the TGF- $\beta$-induced EMT in PCa cells and explore the underlying downstream signaling mechanism. Our results demonstrated that DEC1 and DEC2 positively and negatively correlated with EMT in PCa PC-3 cells, respectively.

\section{Materials and methods}

Cell culture and treatment. Human prostate cancer PC-3 cells from RIKEN BioResource Center (Tsukuba, Japan) were cultured as described previously (21). Cells were incubated with various concentrations of recombinant human TGF- $\beta$ (R\&D Systems, Inc., Minneapolis, MN, USA) for the indicated period of time.

Short interfering RNA (siRNA) and transfection. The siRNAs targeting DEC1 and DEC2, as well as a scrambled non-specific sequence that served as a negative control, were synthesized by Invitrogen; Thermo Fisher Scientific, Inc. (Waltham, MA, USA). The sequences of DEC1, DEC2, and the negative control siRNA have been described previously (22). PC-3 cells were seeded in six-well plates at a density of $5 \times 10^{4}$ per well and then transfected with the negative control siRNA or the siRNA against DEC1 or DEC2 using Lipofectamine RNA iMAX reagent (Invitrogen; Thermo Fisher Scientific, Inc.) in accordance with the manufacturer's instructions. Twenty-four $\mathrm{h}$ after transfection, the medium was replaced with antibiotics-free medium, and the cells were treated with TGF- $\beta$ for another $24 \mathrm{~h}$ and subjected to various analyses.

DEC1 and DEC2 overexpression. Human DEC1 and DEC2 plasmids were kindly gifted from Dr Katsumi Fujimoto (Hiroshima University) (17). PC-3 cells were seeded at $5 \times 10^{4}$ cells per $35-\mathrm{mm}$ well. DEC1 or DEC2 expression plasmid was introduced into cells using Lipofectamine LTX (Invitrogen; Thermo Fisher Scientific, Inc.) according to the manufacturer's protocols. After $18 \mathrm{~h}$ of transfection, the cells were incubated with $10 \mathrm{ng} / \mathrm{ml}$ TGF- $\beta$ for an additional $24 \mathrm{~h}$ and subjected to reverse transcription-polymerase chain reaction (RT-PCR) or western blot analysis.

Reverse transcription-polymerase chain reaction ( $R T-P C R)$. Total RNA was extracted from cells with an RNeasy Mini kit (Qiagen GmbH, Hilden, Germany) and was used for reverse transcription. First-strand cDNA was synthesized from $1 \mu \mathrm{g}$ of total RNA using ReverTra Ace (Toyobo Co., Ltd., Osaka, Japan). RT-PCR was performed using Taq PCR Master mix (Qiagen). The sequences of the primers and the sizes of the amplification products are shown in Table I. The products were analyzed by electrophoresis on 1.5\% (w/v) agarose gels that were stained with ethidium bromide.

Western blot analysis. Cells were lysed using M-PER lysis buffer (Thermo Fisher Scientific, Inc.), and protein concentrations were quantified by the bicinchoninic acid (BCA) assay. The obtained lysates (10 $\mu \mathrm{g}$ protein) were run on a $10 \%$ polyacrylamide gel to separate proteins and were then transferred to polyvinylidene difluoride (PVDF) membranes (Immobilon P; EMD Millipore, Billerica, MA, USA). After blocking with 5\% non-fat milk solution, the membranes were probed overnight at $4^{\circ} \mathrm{C}$ with primary antibodies, followed by incubating with a horseradish peroxidase-conjugated secondary antibody. The bands were visualized using a Bio-Rad western blotting system (Bio-Rad Laboratories, Inc., Hercules, CA, USA) with the ECL-prime western blot analysis detection system (GE Healthcare Life Sciences, Little Chalfont, UK).

Immunofluorescence staining. PC-3 cells were seeded in a four-well chamber slide and fixed with $4 \%$ paraformaldehyde (Wako Pure Chemical Industries, Ltd., Osaka, Japan). The permeabilized cells were incubated with anti-E-cadherin (1:100), anti-N-cadherin (1:100), or anti-vimentin (1:200) antibodies at $4{ }^{\circ} \mathrm{C}$ overnight, followed by Alexa Fluor 488-conjugated secondary antibodies (Invitrogen; Thermo Fisher Scientific, Inc.) at $37^{\circ} \mathrm{C}$ for $1 \mathrm{~h}$. Nuclear staining was performed using 4',6-diamidino-2-phenylindole (DAPI). Fluorescent confocal imaging was performed using a fluorescent microscope (BZ-X700; Keyence Corporation, Osaka, Japan).

Wound healing assay. PC-3 cells were seeded in a four-well chamber slide to reach confluence and then a 'wound' was created at $0 \mathrm{~h}$ in the cell monolayers with a P-200 pipette tip. Subsequently, the medium was immediately changed and the cells were transfected with control siRNA, or siRNA against DEC1 or DEC2 accompanied with TGF- $\beta$. Images were taken at 0,24 , and $48 \mathrm{~h}$ with a phase-contrast inverted microscope.

\section{Results}

Effects of TGF- $\beta$ on DEC expression and EMT-related factors in PC-3 cells. Our previous study reported that TGF- $\beta$ induced the expression of DEC1, while it reduced that of DEC2 in human esophageal squamous cell carcinoma TE-11 cells (23). In the present study, we firstly examined the expression of DEC1 and DEC2 in PC-3 cells in response to various concentrations of TGF- $\beta$ by western blotting and RT-PCR. In PC-3 cells, TGF- $\beta$ increased the expression of DEC1, but decreased that of DEC2 in a dose-dependent manner. The expression of the EMT-related factor E-cadherin was inhibited, whereas $\mathrm{N}$-cadherin and vimentin were upregulated by TGF- $\beta$ (Fig. 1A and B). Moreover, TGF- $\beta$ led to the phosphorylation of Smad2 but not of Smad3 (Fig. 1B, data for pSmad3 not shown).

DECl expression positively correlated with the expression of EMT-related factors in PC-3 cells, whereas DEC2 expression showed the opposite trend. To investigate the roles of DEC1/DEC2 in the TGF- $\beta$-induced EMT of PC-3 cells, the 
Table I. Sequences of the primer sets and the product sizes of RT-PCR.

\begin{tabular}{|c|c|c|c|}
\hline Gene & Product size (bp) & Cycles & Primer sequences \\
\hline$D E C 1$ & 534 & 27 & $\begin{array}{l}\text { F: 5'-GTCTGTGAGTCACTCTTCAG-3' } \\
\text { R:5'-GAGTCTAGTTCTGTTTGAAGG-3' }\end{array}$ \\
\hline$D E C 2$ & 501 & 27 & $\begin{array}{l}\text { F: 5'-CACCTTTGACGTCTTTGGAG-3' } \\
\text { R: 5'-GAGAGTGGGAATAGATGCAC-3' }\end{array}$ \\
\hline E-cadherin & 200 & 27 & $\begin{array}{l}\text { F: 5'-TGCCCAGAAAATGAAAAAGG-3' } \\
\text { R: 5'-GTGTATGTGGCAATGCGTTC-3' }\end{array}$ \\
\hline$N$-cadherin & 201 & 29 & $\begin{array}{l}\text { F: 5'-ACAGTGGCCACCTACAAAGG-3' } \\
\text { R: 5'-CCGAGATGGGGTTGATAATG-3' }\end{array}$ \\
\hline Vimentin & 301 & 29 & $\begin{array}{l}\text { F: 5'-CTTCGCCAACTACATCGACAA-3' } \\
\text { R: 5'-CGCATTGTCAACATCCTGTC-3' }\end{array}$ \\
\hline $18 s r R N A$ & 151 & 20 & $\begin{array}{l}\text { F: 5'-GTAACCCGTTGAACCCCATT-3' } \\
\text { R: 5'-CCATCCAATCGGTAGTAGCG-3' }\end{array}$ \\
\hline
\end{tabular}

RT-PCR, reverse transcription-polymerase chain reaction; F, forward primer; R, reverse primer.

A

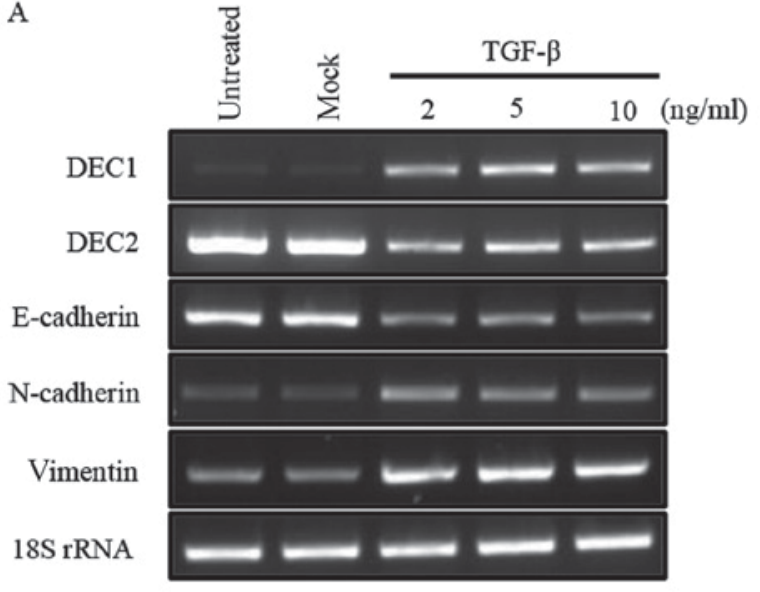

B

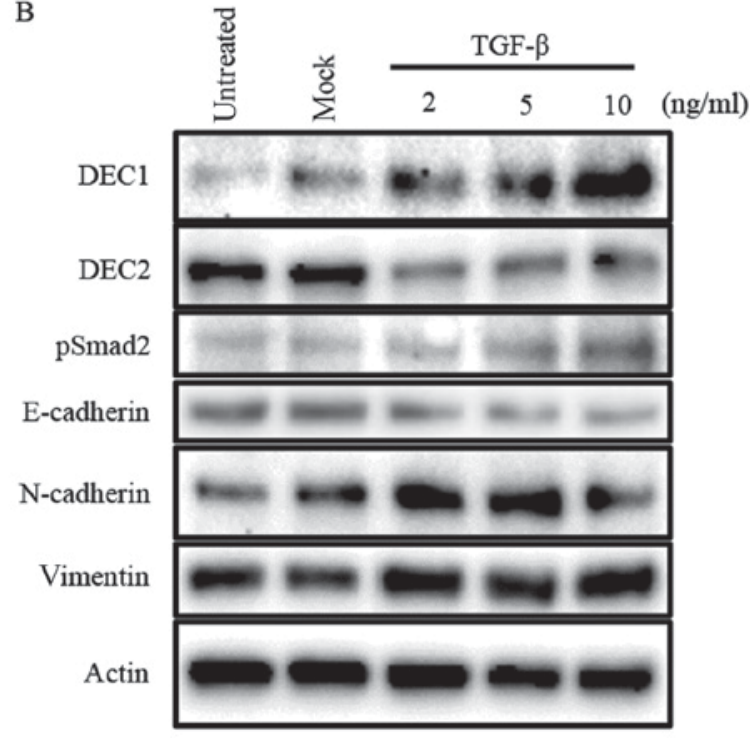

Figure 1. TGF- $\beta$ effects the expression of DEC1, DEC2, and EMT-related factors. (A) PC-3 cells were untreated, mock-treated (buffer alone), or treated with $2,5,10 \mathrm{ng} / \mathrm{ml}$ of TGF- $\beta$. After $24 \mathrm{~h}$, total RNA was prepared and subjected to RT-PCR analyses of DEC1, DEC2, E-cadherin, N-cadherin, vimentin, and $18 \mathrm{~S}$ rRNA. PC-3 cells were treated with TGF- $\beta$ for $24 \mathrm{~h}$. (B) The cells were lysed and the lysates were subjected to western blot analyses of DEC1, DEC2, pSmad2, E-cadherin, $\mathrm{N}$-cadherin, vimentin, and actin.

knockdown or overexpression of DEC1/DEC2 combined with TGF- $\beta$ treatment was carried out in PC-3 cells. The effect of DEC1 on Smad2 phosphorylation was not clearly detected without TGF- $\beta$ (Fig. 2B and D). However, DEC1 knockdown significantly inhibited TGF- $\beta$-induced Smad 2 phosphorylation when compared with the control siRNA group (Fig. 2B). Consequently, the upregulation of the epithelial marker E-cadherin and the downregulation of the mesenchymal markers $\mathrm{N}$-cadherin and vimentin were observed in DEC1 siRNA-transfected PC-3 cells (Fig. 2A and B). As a further experiment, we examined the same genes and proteins in $\mathrm{PC}-3$ cells engineered to overexpress DEC1 pcDNA. The results of this experiment also showed that DEC1 expression positively correlated with that of the mesenchymal markers but negatively correlated with that of the epithelial markers (Fig. 2C and D).
Our results also showed that DEC2 negatively regulated the phosphorylation of Smad2 in the presence of TGF- $\beta$ (Fig. $2 \mathrm{~F}$ and $\mathrm{H}$ ). However, even in the absence of TGF- $\beta$, DEC2 siRNA-transfected PC-3 cells partly lost their expression of E-cadherin, while they gained the expression of $\mathrm{N}$-cadherin and vimentin. Correspondingly with this, DEC2 overexpression dramatically attenuated the expression of $\mathrm{pSmad} 2, \mathrm{~N}$-cadherin, and vimentin, whereas it increased that of E-cadherin (Fig. $2 \mathrm{G}$ and H). The presence of TGF- $\beta$ further augmented these changes at both the mRNA and protein levels (Fig. 2E-H).

Effects of DEC1/DEC2 knockdown on cell morphological changes and the expression of EMT-related factors. Since a fibroblast-like change in cell morphology is an important feature 

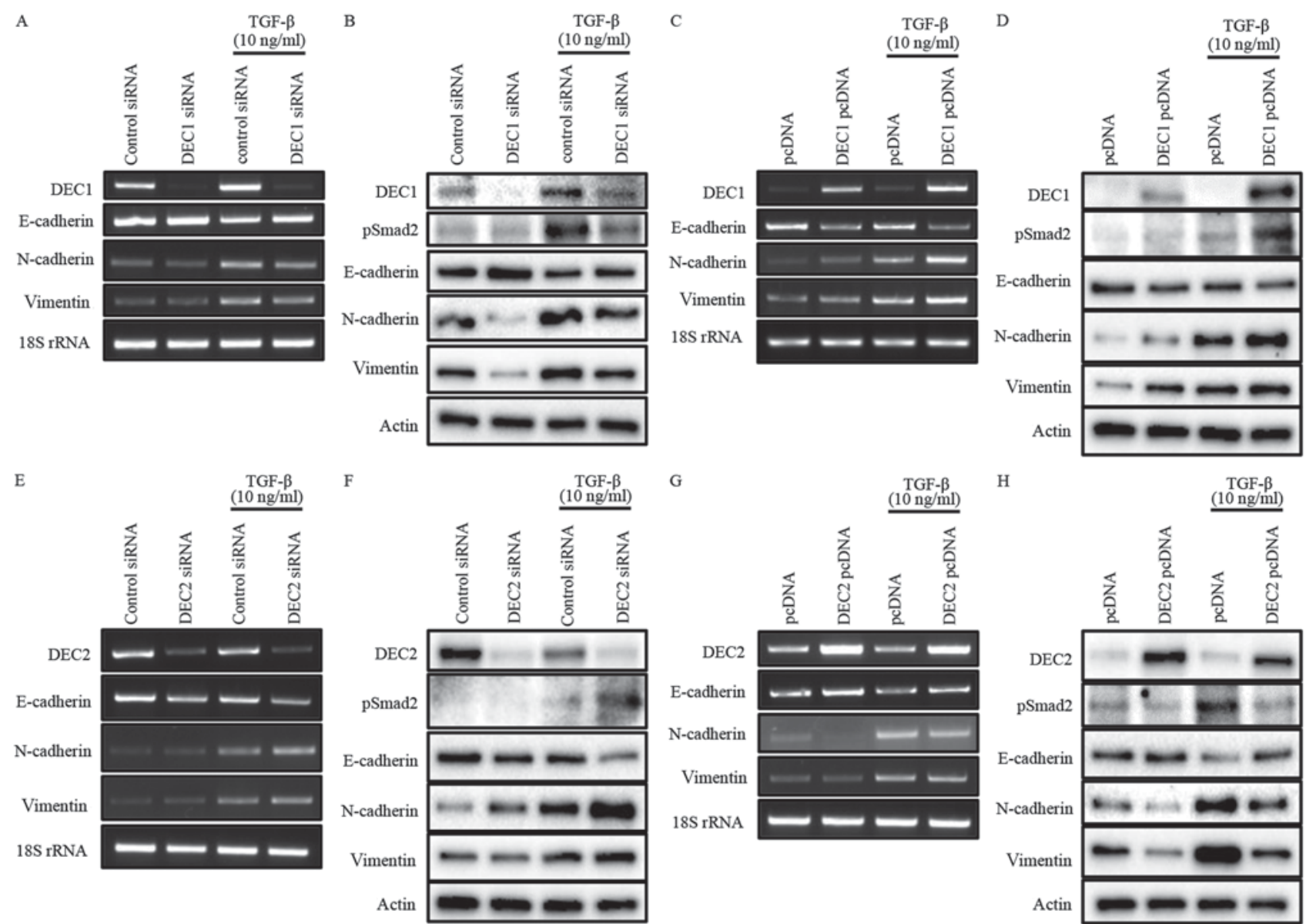

Figure 2. (A-H) Opposite roles of DEC1 and DEC2 in regulating EMT induced by TGF- $\beta$. PC-3 cells were transfected with the siRNAs ( $24 \mathrm{~h}$ transfection) or the expression plasmids (18 $\mathrm{h}$ transfection) of DEC1 and DEC2; subsequently, the cells were incubated with or without TGF- $\beta$ (10 ng/ml) for an additional $24 \mathrm{~h}$. (A, C, E and G) Total RNA was prepared and subjected to RT-PCR analyses of DEC1 or DEC2, E-cadherin, N-cadherin, vimentin, and 18S rRNA. (B, D, F, and H) Protein was prepared from the cells and subjected to western blot analyses of DEC1 or DEC2, pSmad2, E-cadherin, N-cadherin, vimentin and actin. One representative result of at least three independent experiments with similar results is shown. DEC1, differentiated embryonic chondrocyte gene 1; DEC2, differentiated embryonic chondrocyte gene 2; EMT, epithelial-mesenchymal transition; RT-PCR, reverse transcription-polymerase chain reaction.

of the EMT, we observed the morphology of PC-3 cells that were treated with the combination of DEC1 or DEC2 knockdown and TGF- $\beta$. The treatment with TGF- $\beta$ increased the number of cells with elongated and fibroblast-like shapes as compared with the untreated cells. We also found that a pre-incubation with DEC1 siRNA resulted in less fibroblast-like shaped cells than were observed in those transfected with control siRNA in the presence of TGF- $\beta$, while more spindle-like cells were observed in the DEC2 siRNA-transfected group (Fig. 3, the left two panels, middle and bottom images). Based on the immunofluorescence staining results, E-cadherin expression was slightly increased (Fig. 3, third and fourth panels from the left, middle images), while the expression of $\mathrm{N}$-cadherin and vimentin was decreased (Fig. 3, fifth to eighth panels from the left, middle images) in DEC1 siRNA-transfected cells when compared with the control siRNA group. Conversely, PC-3 cells transfected with DEC2 siRNA displayed a reverse pattern to that exhibited in the DEC1 siRNA-transfected cells (Fig. 3, third to eighth panels from the left, bottom images).

Effects of DEC1/DEC2 knockdown on migration capacity of $P C-3$ cells. Metastasis is the principal cause of cancer death, and cell migration is a hallmark of cancer metastasis. Thus, a wound healing assay was employed to evaluate the effects of DEC on the migration ability of PC-3 cells. DEC1 siRNA-transfected cells treated with TGF- $\beta$ for both 24 and 48 h exhibited a slower migration speed when compared with the control siRNA-transfected cells (Fig. 4, images of middle line), whereas DEC2 siRNA-transfected PC-3 cells migrated quickly, especially in the presence of TGF- $\beta$ (Fig. 4, images of bottom line).

\section{Discussion}

It is well accepted that the EMT plays very important roles in tumor progression, especially in cancer cell invasion and metastasis. EMT is mainly controlled by a cadherin switch that is localized in the cell membrane and is characterized by a shift from apical-basal polarity to front-back end polarity, a modification of cell morphology, and a gain of cellular migration activity. A reduction or absence of E-cadherin expression and increased $\mathrm{N}$-cadherin and/or vimentin expression were observed in PCa with high Gleason Scores, and the expression of these markers has been reported to correlate with the metastasis and aggressiveness of PCa $(24,25)$. Among the numerous genes and signaling pathways involved in the EMT, TGF- $\beta$ is recognized as the primary inducer of EMT by activating 


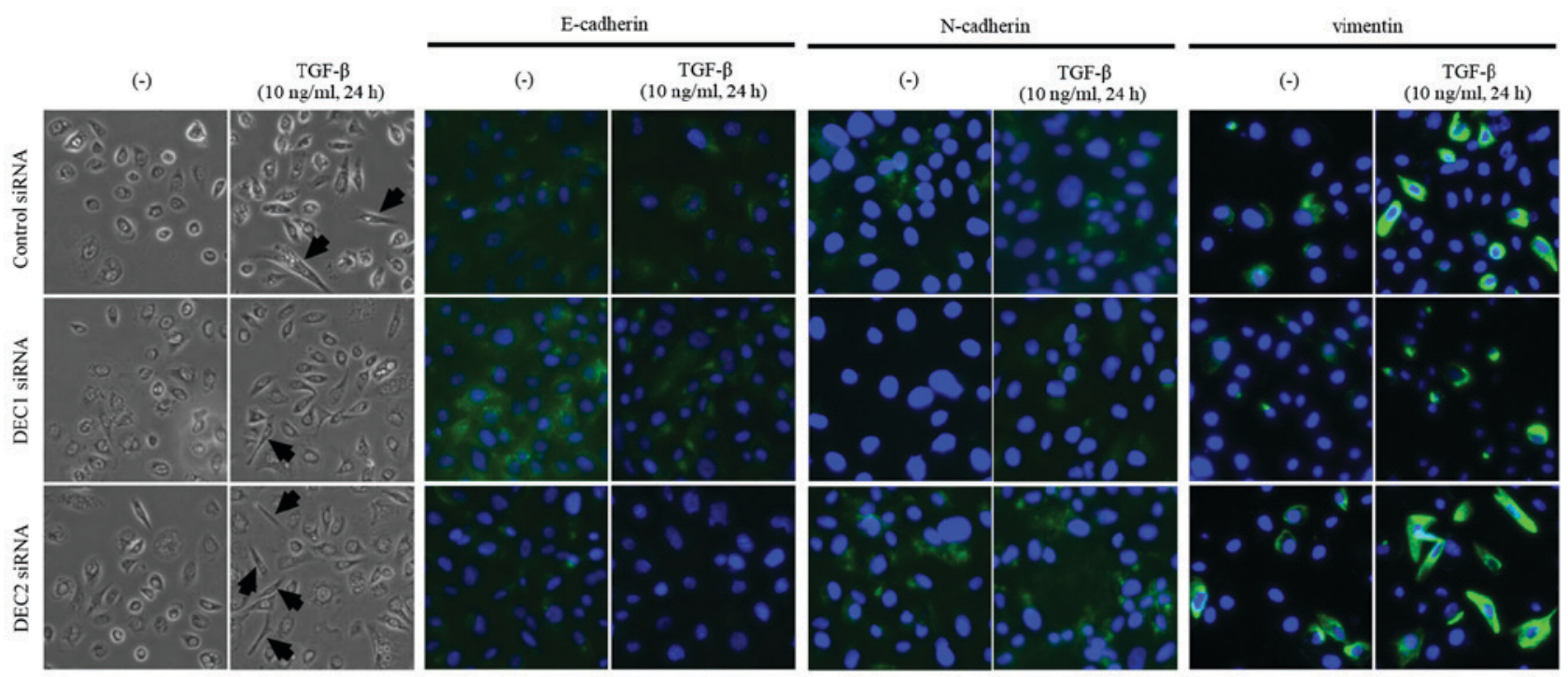

Figure 3. Effects of DEC1/DEC2 on cell morphology and the abundance of cytoplasmic EMT-related factors in PC-3 cells. PC-3 cells were transfected with DEC1 siRNA or DEC2 siRNA, followed by culture with or without TGF- $\beta(10 \mathrm{ng} / \mathrm{ml})$ for $24 \mathrm{~h}$. Cell morphological changes were recorded by bright-phase microscopy (magnification, $\mathrm{x} 400$ ). The cells were then fixed, incubated with antibodies against E-cadherin, $\mathrm{N}$-cadherin, or vimentin and visualized using an Alexa Fluor 488-conjugated secondary antibody (green). Nuclei were stained with DAPI (blue). One representative image (magnification, x400) of three independent experiments with similar results is shown. The black arrows indicate fibroblast-like cells. DEC1, differentiated embryonic chondrocyte gene 1; DEC2, differentiated embryonic chondrocyte gene 2; EMT, epithelial-mesenchymal transition.

$0 \mathrm{~h}$

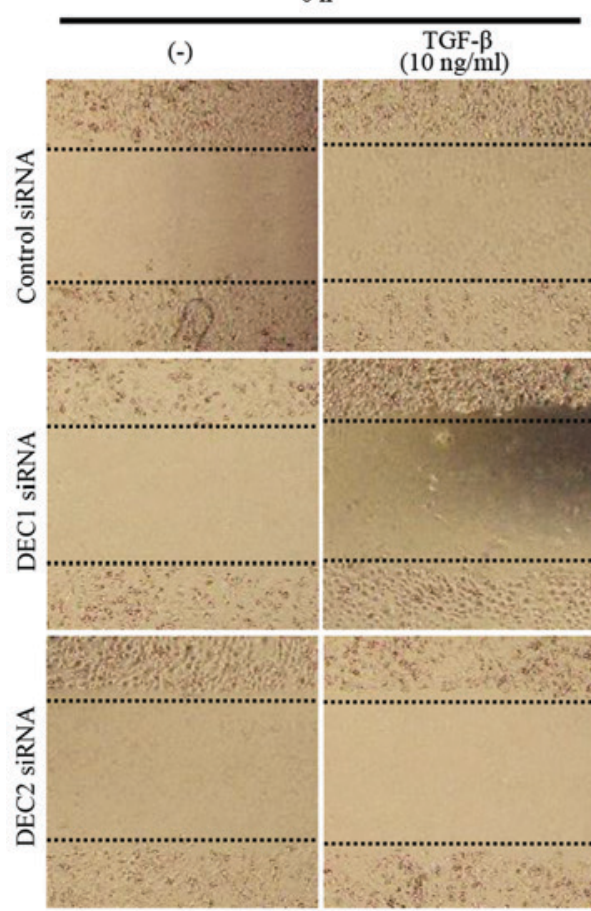

$24 \mathrm{~h}$

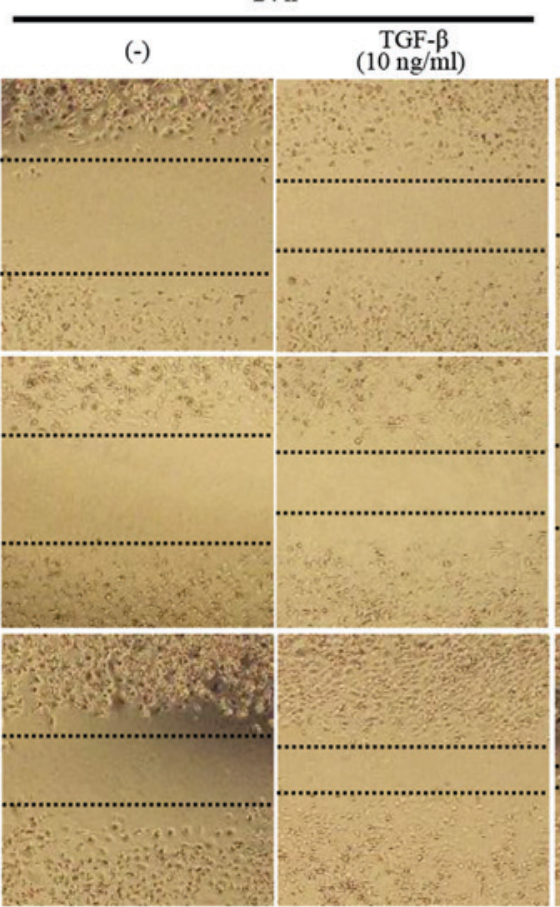

$48 \mathrm{~h}$

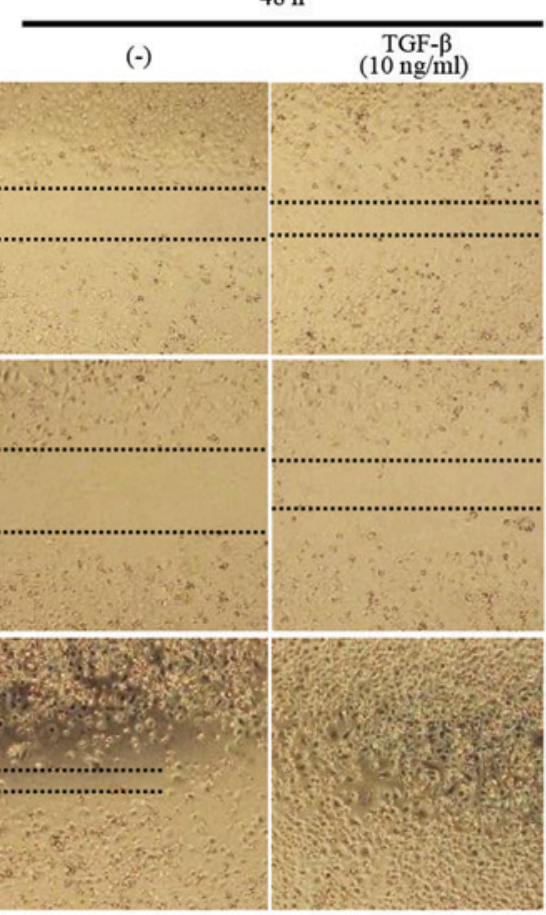

Figure 4. Roles of DEC1/DEC2 in the cell migration of PC-3 cells. PC-3 cells grown in a monolayer were scratched using a pipette tip (P-200 pipette). The cells were then transfected with siRNA against DEC1 or DEC2 and cultured for $24 \mathrm{~h}$. Photographs were taken (magnification, $\mathrm{x} 40$ ) at 0,24 , and $48 \mathrm{~h}$ after adding TGF- $\beta$ (10 ng/ml). DEC1, differentiated embryonic chondrocyte gene 1; DEC2, differentiated embryonic chondrocyte gene 2.

canonical or non-canonical pathways (26). In canonical TGF- $\beta$ signaling, binding to the type II/I receptor complex leads to the phosphorylation of Smad 2/3, followed by an interaction of Smad2/3 with Smad4 and nuclear translocation (11). The expression of the representative epithelial and mesenchymal markers E-cadherin and $\mathrm{N}$-cadherin then changes, resulting in decreased cell adhesion and enhancement of migration. The inhibition of TGF- $\beta$ signaling has been emerging as a therapeutic strategy owing to its functions in the development of cancer, including its roles in the EMT and metastasis $(27,28)$.

Our previous report showed that DEC1 promoted the EMT through the activation of the TGF- $\beta /$ Smad signaling pathway in human pancreatic cancer PANC-1 cells (20). In the present study, we demonstrated that TGF- $\beta$ increased DEC1 but 
decreased DEC2 expression in PC-3 cells, accompanied by the phosphorylation of Smad2, as well as an altered expression of E-cadherin, $\mathrm{N}$-cadherin, and vimentin. Additionally, the treatment of PC- 3 cells with $10 \mathrm{ng} / \mathrm{ml} \mathrm{TGF-} \beta$ induced a change to a spindle-shaped morphology, which indicated the alteration of cell polarity. Since upregulated cell motility is another major feature of the EMT, a wound healing assay was carried out to estimate the effects of DEC on the migration capacity of TGF- $\beta$-treated PC- 3 cells. The results showed that the migratory capacity was slightly decreased by DEC1 siRNA, while it was significantly increased by DEC 2 siRNA. These findings implicated that TGF- $\beta$ is sufficient for EMT induction in PC-3 cells and TGF- $\beta$-induced DEC expression might somewhat relate to the EMT process.

As a crucial downstream mediator of the TGF- $\beta$ signaling pathway, Smad 2 protein is phosphorylated by the TGF- $\beta$ receptor and mediates the intracellular signal transduction of TGF- $\beta$. The present study demonstrated that in the absence of TGF- $\beta$, the knockdown or overexpression of DEC altered the expression of EMT-related factors without Smad2 phosphorylation. In the presence of TGF- $\beta$, EMT-related factors were remarkably changed by DEC siRNA or expression plasmids. We concluded that DEC could regulate EMT-related factors independently of pSmad2, but as an enhancer, DEC collaborated with Smad2 and augmented its function of regulating the translation of the target proteins. Notably, DEC1 and DEC2 exhibited different effects on EMT-related markers. The differences between DEC1 and DEC2 with regard to their functions may be partially caused by the differences in the protein structure of their C-terminals.

Based on these results, we propose the hypothesis that DEC1 and DEC2 have distinct roles in the process of EMT in cancer cells. This hypothesis merits addressing in future studies, especially, the details of the molecular mechanisms for the transcriptional regulation of EMT markers by DECs should be further investigated. Furthermore, future studies should investigate whether DECs may represent potential molecular targets for the management of aggressive PCa.

\section{Acknowledgements}

The authors would like to thank Professor Yukio Kato and Dr Katsumi Fujimoto at the Department of Dental and Medical Biochemistry, Hiroshima University Graduate School of Biomedical for kindly providing the plasmids.

\section{Funding}

The present study was supported by Grants-in-Aid for Science from the Ministry of Education, Culture, Sports, Science and Technology of Japan (grant nos. 17K17575 and 17H04057).

\section{Availability of data and materials}

The datasets used and/or analyzed during the current study are available from the corresponding author on reasonable request.

\section{Authors' contributions}

YW and HK conceived and designed the study. YW and QL designed the methods, analyzed the data, interpreted the results and drafted and reviewed the manuscript. QL executed all of the experiments. HS, TH, TY and SM contributed to data interpretation and critically reviewed the manuscript. All authors contributed to, read and approved the manuscript.

\section{Ethics approval and consent to participate}

Not applicable.

\section{Patient consent for publication}

Not applicable.

\section{Competing interests}

The authors declare that they have no competing interests.

\section{References}

1. Siegel RL, Miller KD and Jemal A: Cancer Statistics, 2017. CA Cancer J Clin 67: 7-30, 2017.

2. Denmeade SR and Isaacs JT: Development of prostate cancer treatment: The good news. Prostate 58: 211-224, 2004.

3. Carlin BI and Andriole GL: The natural history, skeletal complications, and management of bone metastases in patients with prostate carcinoma. Cancer 88 (12 Suppl): S2989-S2994, 2000.

4. Bubendorf L, Schöpfer A, Wagner U, Sauter G, Moch H, Willi N, Gasser TC and Mihatsch MJ: Metastatic patterns of prostate cancer: An autopsy study of 1,589 patients. Hum Pathol 31: 578-583, 2000.

5. Valastyan S and Weinberg RA: Tumor metastasis: Molecular insights and evolving paradigms. Cell 147: 275-292, 2011.

6. Thiery JP, Acloque H, Huang RY and Nieto MA: Epithelial-mesenchymal transitions in development and disease. Cell 139: 871-890, 2009.

7. Kalluri R and Weinberg RA:The basics of epithelial-mesenchymal transition. J Clin Investig 119: 1420-1428, 2009.

8. Xu J, Lamouille S and Derynck R: TGF-beta-induced epithelial to mesenchymal transition. Cell Res 19: 156-172, 2009.

9. Miettinen PJ, Ebner R, Lopez AR and Derynck R: TGF-beta induced transdifferentiation of mammary epithelial cells to mesenchymal cells: Involvement of type I receptors. J Cell Biol 127: 2021-2036, 1994.

10. Miyazono K: Transforming growth factor-beta signaling in epithelial-mesenchymal transition and progression of cancer. Proc Jpn Acad Ser B Phys Biol Sci 85: 314-323, 2009.

11. Brown KA, Pietenpol JA and Moses HL: A tale of two proteins: Differential roles and regulation of Smad2 and Smad3 in TGF-beta signaling. J Cell Biochem 101: 9-33, 2007.

12. Matsuzaki K: Smad phosphoisoform signaling specificity: The right place at the right time. Carcinogenesis 32: 1578-1588, 2011.

13. Moustakas A and Heldin CH: Non-Smad TGF-beta signals. J Cell Sci 118: 3573-3584, 2005.

14. Reis ST, Pontes-Júnior J, Antunes AA, Sousa-Canavez JM, Abe DK, Cruz JA, Dall'oglio MF, Crippa A, Passerotti CC, Ribeiro-Filho LA, et al: Tgf- $\beta 1$ expression as a biomarker of poor prognosis in prostate cancer. Clinics (Sao Paulo) 66: 1143-1147, 2011.

15. Wikström P, Stattin P, Franck-Lissbrant I, Damber JE and Bergh A: Transforming growth factor betal is associated with angiogenesis, metastasis, and poor clinical outcome in prostate cancer. Prostate 37: 19-29, 1998.

16. Sun $\mathrm{H}$ and Taneja R: Stra13 expression is associated with growth arrest and represses transcription through histone deacetylase (HDAC)-dependent and HDAC-independent mechanisms. Proc Natl Acad Sci USA 97: 4058-4063, 2000.

17. Honma S, Kawamoto T, Takagi Y, Fujimoto K, Sato F, Noshiro M, Kato Y and Honma K: Dec1 and Dec2 are regulators of the mammalian molecular clock. Nature 419: 841-844, 2002.

18. Li Y, Xie M, Yang J, Yang D, Deng R, Wan Y and Yan B: The expression of antiapoptotic protein survivin is transcriptionally upregulated by DEC1 primarily through multiple sp1 binding sites in the proximal promoter. Oncogene 25: 3296-3306, 2006. 
19. Chakrabarti J, Turley H, Campo L, Han C, Harris AL, Gatter KC and Fox SB: The transcription factor DEC1 (stra13, SHARP2) is associated with the hypoxic response and high tumour grade in human breast cancers. Brit J Cancer 91: 954-958, 2004.

20. Wu Y, Sato F, Yamada T, Bhawal UK, Kawamoto T, Fujimoto K, Noshiro M, Seino H, Morohashi S, Hakamada K, et al: The BHLH transcription factor DEC1 plays an important role in the epithelial-mesenchymal transition of pancreatic cancer. Int J Oncol 41: 1337-1346, 2012.

21. Liu Q, Wu Y, Yoshizawa T, Yan X, Morohashi S, Seino H, Kato Y and Kijima H: Basic helix-loop-helix transcription factor DEC2 functions as an anti-apoptotic factor during paclitaxel-induced apoptosis in human prostate cancer cells. Int J Mol Med 38: 1727-1733, 2016.

22. Liu Y, Sato F, Kawamoto T, Fujimoto K, Morohashi S, Akasaka H Kondo J, Wu Y, Noshiro M, Kato Y and Kijima H: Anti-apoptotic effect of the basic helix-loop-helix (bHLH) transcription factor DEC2 in human breast cancer cells. Genes Cells 15: 315-325, 2010.

23. Wu Y, Liu Q, Yan X, Kato Y, Tanaka M, Inokuchi S, Yoshizawa T, Morohashi S and Kijima H: Podoplanin-mediated TGF- $\beta$-induced epithelial-mesenchymal transition and its correlation with bHLH transcription factor DEC in TE-11 cells. Int J Oncol 48: 2310-2320, 2016.
24. Tomita K, van Bokhoven A, van Leenders GJ, Ruijter ET, Jansen CF, Bussemakers MJ and Schalken JA: Cadherin switching in human prostate cancer progression. Cancer Res 60: 3650-3654, 2000.

25. Jennbacken K, Tesan T, Wang W, Gustavsson H, Damber JE and Welén K: N-cadherin increases after androgen deprivation and is associated with metastasis in prostate cancer. Endocr Relat Cancer 17: 469-479, 2010.

26. Yang J and Weinberg RA: Epithelial-mesenchymal transition: At the crossroads of development and tumor metastasis. Dev Cell 14: 818-829, 2008.

27. Jones E, Pu H and Kyprianou N: Targeting TGF-beta in prostate cancer: Therapeutic possibilities during tumor progression. Expert Opin Ther Targets 13: 227-234, 2009.

28. Massagué J: TGFbeta in cancer. Cell 134: 215-230, 2008. Attribution-NonCommercial-NoDerivatives 4.0 International (CC BY-NC-ND 4.0) License. 